\title{
APPROACH TO STRUCTURAL ANALYSIS OF ENVIRONMENTAL SCIENCE
}

\author{
Gotfrids Noviks \\ Rezeknes augstskola, Latvia
}

\begin{abstract}
The paper discusses the essence, structure, research objects, methods and aims of the environmental science.

Due to interdisciplinary character of the environmental science, large scale term and vague boundaries with other sciences there are various definitions of environmental science and different concepts, sometime delusions in research fields and methods .

Author analysed the current location of research objects in environmental science and their connection with other sciences and came to conclusion that up to nowadays there are not developed essential part of every independent science yet - general theoretical base of environmental science.

It is necessary to find out perfect proper research fields and objects of environmental science, which differ from other natural, and technical sciencies.

Analysis showed that the objects of environmental science must be neither nature nor technology itself but only contact zones between technosphere and biosphere -namely, between systems - technosystems and ecosystems . Exactly in these contact zones arises most environmental problems, conflicts and stresses between human activities and nature .

The properties and processes in these zones obey to laws which must be determined, interpreted and used for mankind wealth.

It is the aim of environmental science and the complex system analysis must be essential research methodology and accordingly system engineering as instrument for solving practical environmental problems.
\end{abstract}

\section{KEYWORDS}

Environmental science, ecology; complex environment systems ; environmental education; technosphere; biosphere .

\section{INTRODUCTION}

Specificity of the environmental science is related to its complex multifactorial structure. Literally the term "environmental science" is very broad.

Generally a title of any science derives from multiple, sometimes subjective, considerations and it is not essential per se.

Usually the title has no reflect on the essence and the content of particular science.

It is different when the content, structure and methodology of the science are not fully formed yet. Then the title can become the reason for various and ambiguous interpretations of the content of the science and the source for misunderstandings.

https://doi.org/10.15626/Eco-Tech.2010.078 
Environmental science is a relatively new field of science. Therefore it is important to clarify terminology and define its content and essence.

The term "environment" has meaning only if a central object exists which has surrounding living organisms and objects, energy and information fluxes, space, social interactions etc constituting an environment.

Any kind of science research area also is environment in its different aspects. It examines an object surrounded by a particular environment.

In this regard the term "environmental science" is not entirely accurate - "environment" is not linked to an object and therefore becomes too broad in comparison with the complex of problems this science deals with. It creates an impression that environmental science is not a completely autonomous science, but conglomerate, artificially comprised with components from other sciences. This view is further enforced by the fact that research areas of environmental science continuously broaden and new sub-sectors of environmental science emerge.

The problem is not new. Issues related to the essence and content of environmental science, its place between other sciences is discussed constantly due to its various definitions. Currently used definitions $[1,2,3,4]$ see environmental science as

- Synonymous to ecology,

- Same as ecology, but including humans in its biota,

- Science of interaction processes between humans and the environment,

- Science of physical and chemical pollution processes,

- Science of problems of pollution, overpopulation, depletion of resources etc.

Components included within the scope of environmental science also vary. Different sources show atmospheric sciences, ecology, environmental chemistry, environmental biology, geological sciences etc. being included.

Therefore views about the place of the environmental science among other sciences vary.

Environmental science is seen as a part of ecology and vice versa - includes ecology, is separated or put on the same level as environmental management, environmental protection, included in the block of Earth sciences or left out of it etc.

Often the definitions of environmental science are formulated following principle of additivity - first they state interdisciplinary nature of the science, which gives a justification for adding the array of problems from other, related scientific fields. Finally, they conclude with comprehensive global aim. [5, 6, 7, 8].

Such constructions cannot distinguish the field of environmental science clearly and unambiguously.

Current voluntary distribution of environmental science research areas across other scientific fields without one nucleus may be illustrated with Figure 1. 
a)

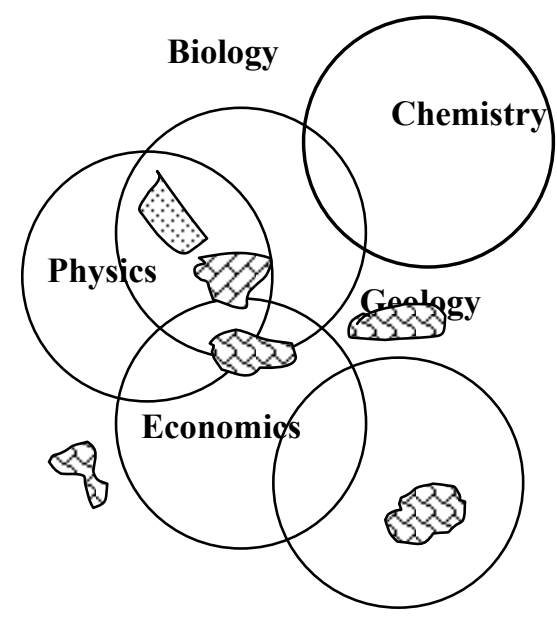

b)

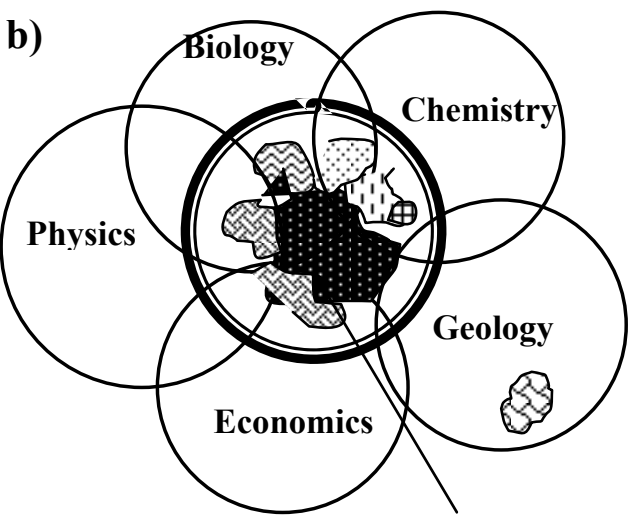

Environmental science

Figure 1.The current (a) and optimal (b) - centred by nucleus of the theory - environmental science research objects in relation to other branches of science.

-problems related to environment science

In Latvia a de-centralized approach prevails not only in environmental education (in schools environmental issues are distributed across different subjects) but also in official nomenclature of scientific degrees. In Latvia, a doctor's degree in environmental science (Dr. env.) as such does not exist. Only doctor's degrees in

biology (Dr.biol.), economy (Dr. oec.), physics (Dr. phys.), geography (Dr. geogr.), chemistry (Dr. chem.) with an extension to environmental science are obtainable. [9]

In addition to that in the Latvian Education Classification environmental protection is included in the thematic group of service industries. [10]

All the above proves that despite large and growing number of researches, problem solving projects and publications, which with different level of concessions can be associated with environmental science, the science itself in its classical meaning has not yet materialized.

At first, any science cannot exist without its nucleus - theory.

Research shows that currently environmental science lacks a theoretical basis forming this science. Environmental science cannot be only a collection of methods of environmental protection, preservation of resources, pollution prevention etc.

Environmental science just as any other science must have developed, researched, proved theory, laws, regularities and methodology that would serve as a base for applied solutions of environmental problems. However, currently in environmental science practical problem solving prevails and development of theory is slow.

Any autonomous science has clearly defined research objects (including processes), research methodology (and methods) that are founded on a common theoretical basis of this scientific field. Let's examine the essence of these parameters in environmental science. 


\section{ENVIRONMENTAL SCIENCE RESEARCH OBJECTS}

The term "environmental science" was created at a time when ecology already existed; furthermore, it was actually a derivation of ecology. This lead to the definitions of "ecology" and "environmental science" being identical and at present they are often perceived as one science. [11]

The term "ecology" in its classical meaning was introduced in 1866 by German scientist Ernst Haeckel [12] but only 10 years later when Danish botanist Johannes Eugenius Warming wrote the first monograph stating theoretical fundamentals of ecology, did it become a science [13]. Ecology as a scientific field gradually expanded its research scope including almost all areas of human activity (int. al. social ecology, human ecology, even ecology of ecosystems). Currently, the original concept of ecology as the science that deals with organisms and their relations with surrounding environment, does not comply with the actual scope of its research. Consequently the definition of ecology is changed. Three main milestones in the development of the term "ecology" are: Haeckel - 1866; Andrewartha, Birch-1954 [14]; E. Odum - 1969 [15]. However, that does not cover all existing definitions.

The number of directions of scientific research that has "ecology" (or "eco") in their title already exceeds 30 and continues to grow. Ecological research areas include objects that comply more with current perceptions of environmental science. [16] Research directions such as "environmental ecology", "industrial ecology" and "agroecology" have emerged.

The main research object of ecology is ecosystem - that is, the combination of biotic and abiotic components in their dynamic development and their interaction.

Unity of biotic and abiotic environment creates a system. Subsequently principles of system analysis can be applied to it. [17] . At the same time these ecological research objects are components of the greater system - natural formation - the biosphere.

Articifial systems made by humans belong to other formation - the technogenic sphere or the technosphere. The technosphere and the biosphere exist in the same space. The biosphere and technosphere are linked to each other and together form a complex system (super system) [18].

Characteristic properties of complex systems are:

- No centralized control,

- Many autonomous heterogeneous components,

- Each subsystem has its own operational purpose,

- Processes are characterized by nonlinear dynamics,

- They mainly are indeterministic, capable of destroying stability and even create chaos.

The subsystems of these complex systems develop by constantly interacting, exchanging energy, matter and information and trying to gain positive results according to their own operational purpose. $[19,20]$

Let's examine the technosphere in this context.

The key structural element of the biosphere is ecosystem, but the key element of technosphere is technogenic system (technosystem, anthroposystem). The technosystems just as ecosystems are controlled by respective laws but they are different.

Ecosystems are natural systems and are controlled by laws of nature whereas technosystems are constructed by humans and controlled by laws set by humans. 
Technosystems and the whole technosphere is part of the biosphere - they occupy space within it, gradually force natural systems out and replace them with artificial ones.

The main conflict is that laws set by humans do not comply with the laws of nature. As rules of nature are primary, absolute and cannot be altered, technogenic systems have to be secondary to the laws of nature.

Contact zones between the technosphere and biosphere (or more precisely technosystems and ecosystems) are dynamic, variable and become zones of conflicts where tension and conflicts arise and environmental protection problems emerge.

There are direct and indirect contact zones. Technosystems are mostly separated from natural systems by a transitional buffer zone - the environment altered and adapted by humans infrastructure that assures quality of level of human life.

This zone is the interaction zone of natural laws and human laws .

As its conditions and efficacy are controlled by human intellect and knowledge conditionally it can be identified as the noosphere in its narrowest meaning according to Theilard de Chardin [21] and V.Vernadsky [22]

These zones are not directly researched by any other science; therefore they are the object of research of environmental science.

As established, the research object of environmental science is neither technology nor nature. Its research object is the contact zone of structural elements of two common systems, the links between the technosphere and biosphere and their interaction processes.

The driving forces of environmental research are: the elimination of internal conflicts in the development of the biosphere and technosphere as a common complex supersystem, harmonization of natural and anthropogenic laws with improvement of the latter according to the former.

\section{RESEARCH METHODS OF ENVIRONMENTAL SCIENCE}

The research area of environmental science is systems. Therefore the cornerstone of an environmental research methodology is systems theory and environmental system analysis.

Criteria of systemic approach (thinking) were developed by biologist Ludwig von Bertalanffy in the third and the forth decades of $20^{\text {th }}$ century released initially in his publications in biology and later in psychology, ecology [23].

A fundamental contribution to the theory of open systems was given in 1970-ties by Nobel Prize laureate Ilya Prigogine who developed the theory of self-organization of dissipative structures. [24]

Systems analysis includes flux of energy and materials, structural analysis of components and their optimization. But the main research tool of systems analysis and therefore environmental science is systems modeling and a whole complex of methods of physical, chemical and biological environmental research.

System analysis provides an opportunity to find exact zones of interacting entities where conflicts emerge. Thus it becomes possible to express conflict mathematically and also to perform analogue and mathematical modeling. As a result, the problem transfers to the category of engineering exercises and can be solved using methods of engineering, including creative engineering problem solving methodology TRIZ [25], which is rooted in system analysis.

The process of analysis and the relationship between the spheres can be illustrated using example of the interaction model where the biosphere, technosphere and noosphere are 
depicted as gearwheels. It shows numerous zones of conflicts and risk (speed of gearwheels, shape, size, number of gears etc). If in the model gearwheels are changed to round reels, the number of potential conflict points and level of risk reduces by $86 \%$.

According to systems theory, complex systems analyse on different levels of hierarchy, separating an individual group of interactive components for each level. For environmental system analysis it is important to determine the correlation between intensity parameters of technology $\mathrm{T}$ (basic structural element of technosphere), environmental quality $\mathrm{V}$ (conditions of natural systems) and resources.

Consumption (the strongest link between nature and technology - input flux) as well as the dynamics of their change.

These links can be examined by constructing a structural triangle "Environment - Technology - Resources" (ETR) diagram ( see Figure 2). The ETR diagram allows comparing different technologies and areas of industry in terms of resources (input of energy and materials) and environmental capacity (acceptable environmental damage) depleting dynamics regardless of particular type of industry. The diagram allows examination of interaction between separate variable parameters and gives the option to make decisions based on it.

The triangle diagram with coordinates "Ecosystem quality - Resources - Human health" was applied in the development of a methodology for production cycle assessment $[26,27]$ and development of eco-indicators for models of the technosphere, ecosphere and valuesphere.

As the main objective of environmental science is to ensure human wellbeing, the system analysis has to be applied to assess correlation between quality of life integral parameter $C_{k}$, intensity of loss of environmental quality $\mathrm{V}_{\mathrm{L}}$ and technological capacity $\mathrm{T}$.

Regularity between these parameters mathematically can be expressed as the equation [28]:

$$
\mathrm{C}_{\mathrm{k}}=\mathrm{a}_{0}+\mathrm{QTt}-\mathrm{V}_{\mathrm{L}} \mathrm{t}_{2}+\mathrm{T}_{2}
$$

where $\mathrm{Q}$ - environmental capacity, $\mathrm{a}_{0}$ - minimum level of quality of living (starting point), $\mathrm{t}-$ time. 


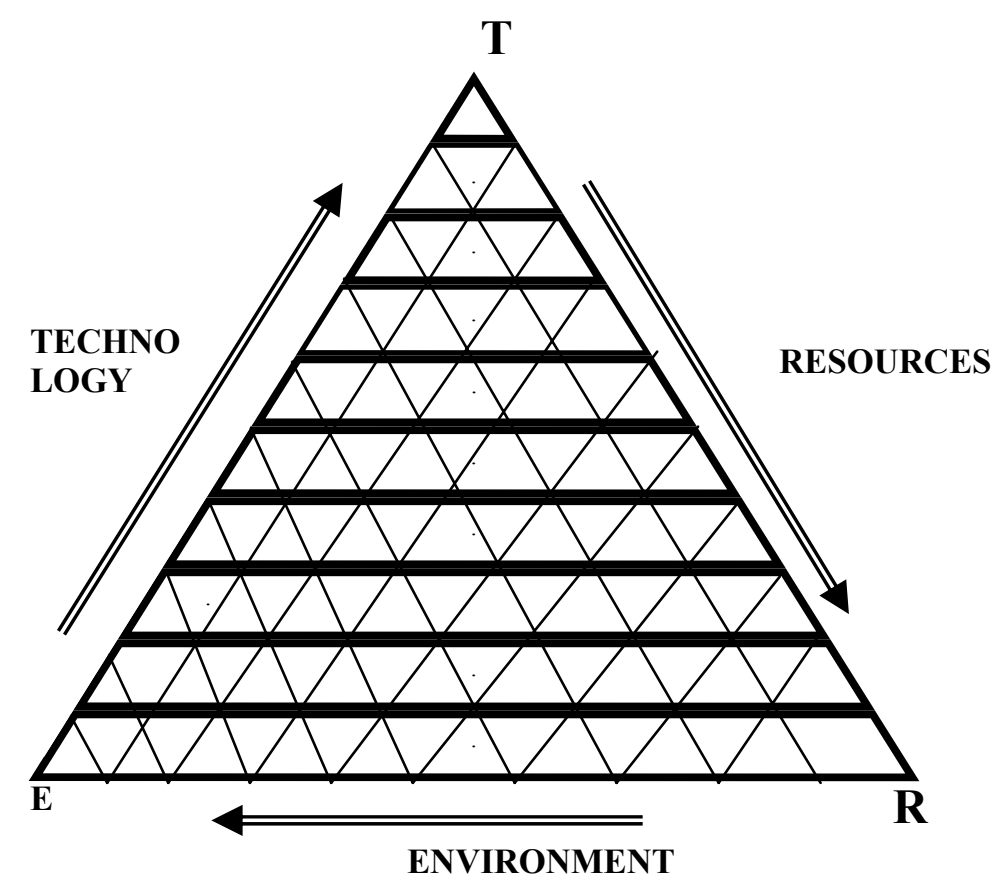

Figure 2. Structural diagram „, Environment-Technology-Resources”

Analysis and modeling of this equation shows that an increase in technological capacity (that sometimes is considered guaranteed solution for all problems) really can provide an increase in quality of living, however, if loss of environmental quality (e.g. pollution) is not reduced at the same time, development of technologies can only delay point of collapse of human wellbeing $\mathrm{t}_{\mathrm{kr}}$ ( see Figure 3, curves $1,2,3$ ). Only if, with increasing technological capacity, parameters of loss of environmental quality at the least stay the same, it is possible to provide sustainable development for humans (Figure 3, curves A, B).

Consequently, it is necessary to modernize technologies and transform them into ecotechnologies but it requires performing successive system analysis of all technological processes and firstly establishing principal opportunities to implement physical effects in constructions according to the equation $\mathrm{C}_{\mathrm{k}}=\mathrm{f}\left(\mathrm{Q}, \mathrm{T}, \mathrm{V}_{\mathrm{L}}\right)$ if $\mathrm{t}_{\mathrm{kr}}=\infty$.

The methodology of the complex theoretical analysis of ecotechnology [29] has two stages:

- determination of implementation probability areas of ecotechnology that consists of determination of boundaries for areas of technical possibility, social and economical effectiveness and environmental warranty- construction of a model of input and output fluxes of energy and matter and its application in evaluation of every technological process and whole technological line, including calculations of effectiveness of resources utilization at successive stages of production and calculations of pollution generation and effectiveness of its treatment at the different stages of production and whole process. 


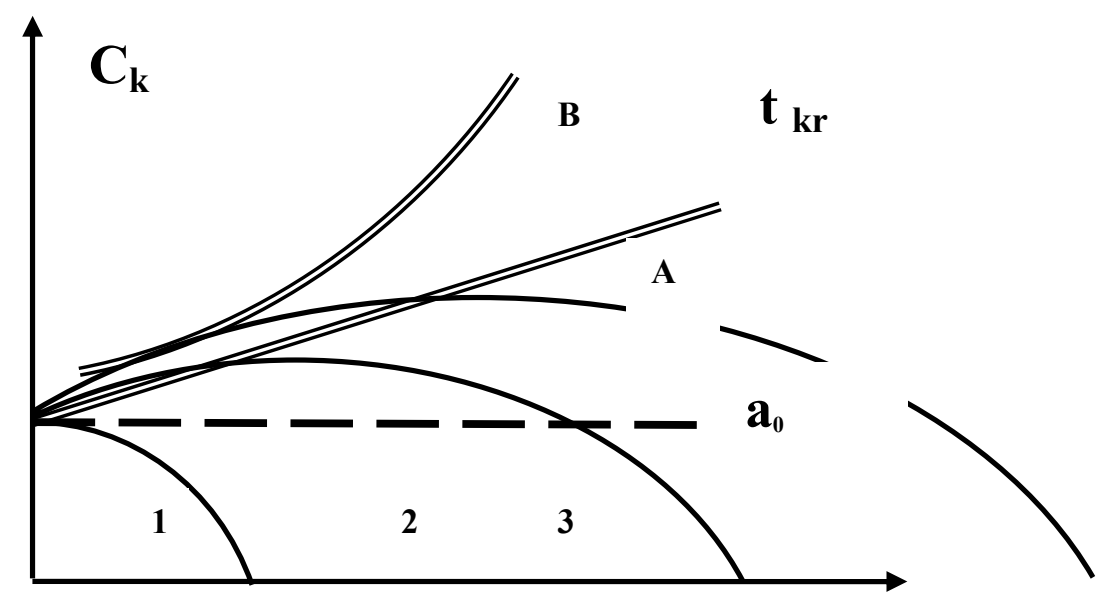

Figure 3. The changes in the quality of human living Ck in the course of time depending on technological growth $E$ and losses of environment quality $V_{L}$

The probability areas of ecotechnologies are shown graphically with coordinates "Effectiveness - Stability" ( see Figure 4) and analytically using their equations.

For any concrete technology problem can be solved if use theoretical equations that limits o technical possibility $S_{t}$, social and economical effectiveness $S_{s}$ and environmental warranty $S_{e}$ areas.

A complex solution of all three equations gives area $S_{0}$ and its optimal limits confining the best paranteters of efficiency, economical and environmental warranty and operational span.

The technological, economical and environmental quality areas can overlap in following ways: fully harmonized, non-conflict (Figure $5-a, b, c$ ), conflict but solvable (Figure 5- $d$, e) and fully un-harmonized (Figure 5-f). [30]

Replacing abstract parameters with parameters of a particular technological process we can determine optimal regimes for a real technology. [31]

Subsequently, ecologisation of technologies is a task of system analysis that is possible to solve using methods of mathematical optimization of processes.

\section{THE AIM OF ENVIRONMENTAL SCIENCE}

It is usually perceived that the aim of environmental science is environmental protection. The first question emerging from analysis of this perception is "what is

environmental protection?" The Latvian classification of the scientific fields offers a broader explanation of the aim: "protection of biological and genetic diversity of natural resources, 
possibility of sustainable existence..." followed by the main point of this definition "protection of humans from negative consequences of their actions".

The rest is only tasks and methods how to achieve this aim. If in distant times protection from environment was understandably crucial for human survival then now

the essence of the problem is not changed in principle. Only at some point in time it was inverted and protection of environment from humans became primary.

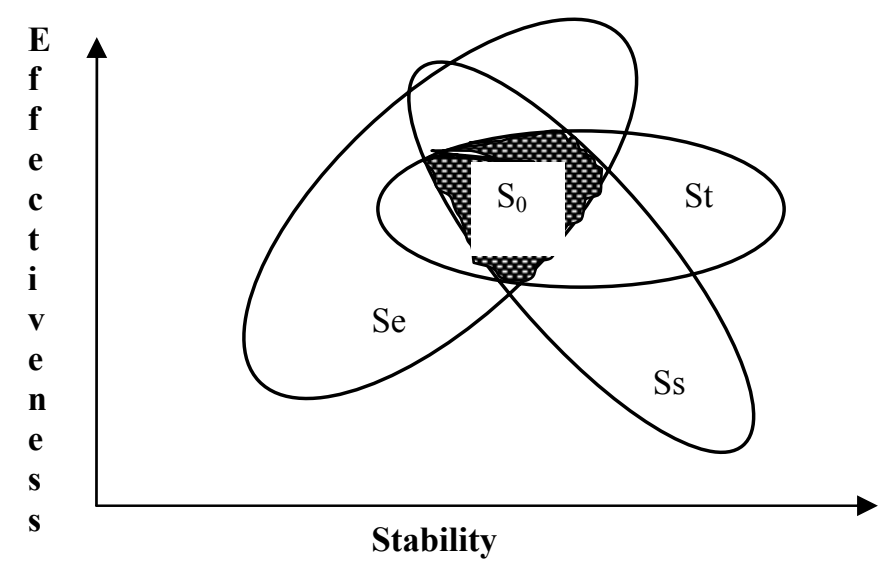

Figure 4. The technological possibility $T$, environment warranty $V$ and economical effectiveness E harmonization areas.

Essentially environmental protection is protection of humans, provision of successful existence of all civilization and development processes. The adverse effect of the nature on humans is not changed and is still the same.

Any action taken by humans in the environment has counteraction. The response from the environment is not adequate, it is multiplicative and the greater load humans

put on the environment, the stronger it becomes with less predictable consequences. This relation mathematically can be described as the equation

$$
\mathrm{R}=-\mathrm{t}^{\mathrm{a}} \cdot \mathrm{I}^{\mathrm{b}} / \mathrm{C} \cdot \rho
$$

where $\mathrm{R}$ - counteraction of the biosphere - a fundamental property of the nature;

$\mathrm{t}$ - time of humans affecting environment; I - intensity of impact; $\mathrm{C}$ - environmental capacity - equilibrium of input and output fluxes of energy and matter; $\rho-$ factor of environmental resistance to external impact; a,b - coefficients of reaction intensity (average a $=2-2,5, b=2,5-4)$. 


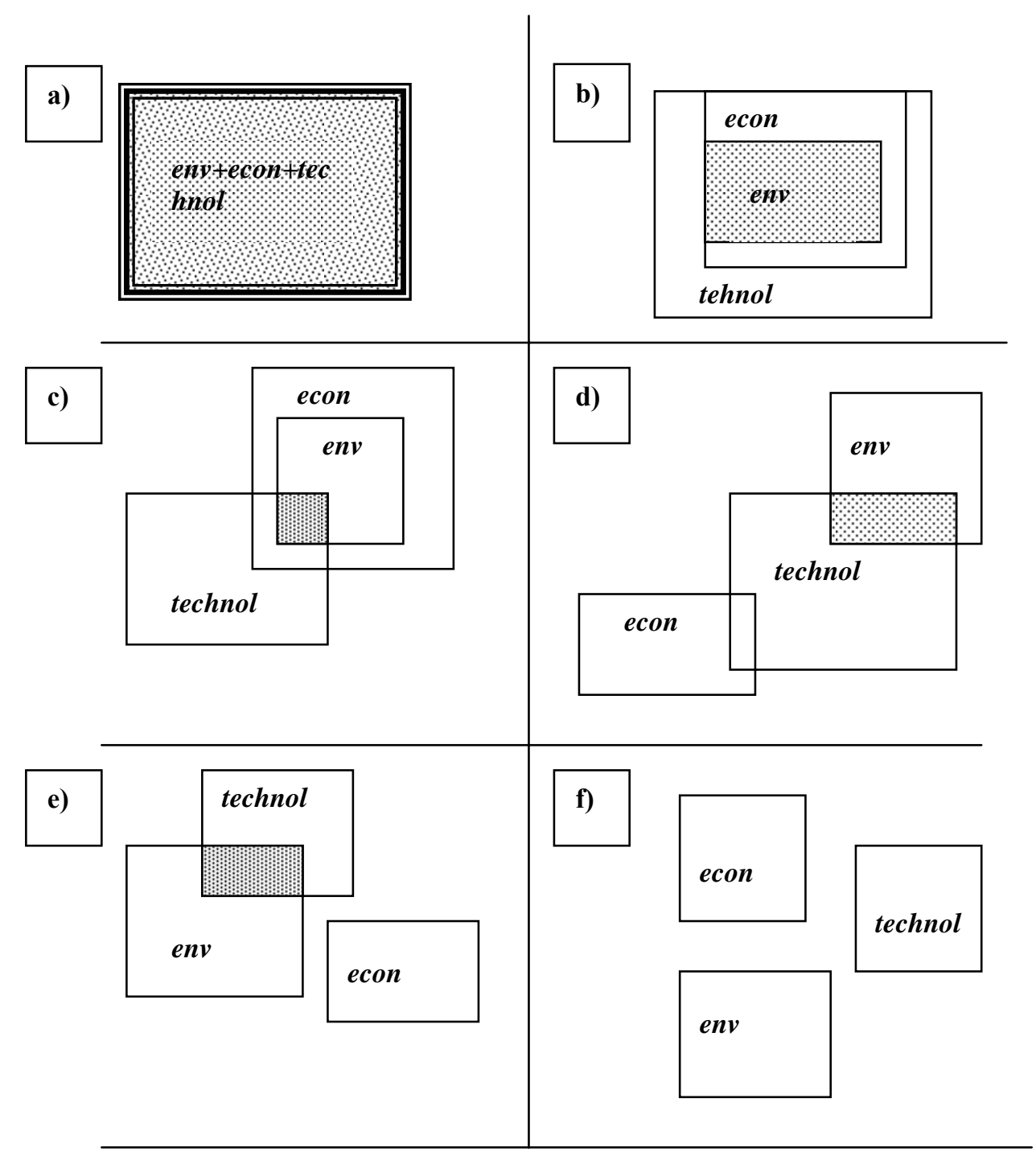

Figure 5. The possible overlapping zones of technological possibility, environmental warranty and economical effectiveness.

Studies of the mechanisms and laws of the co-existence process of these two systems in a unified super system, regularities determining this interaction and development of methods to apply findings in solutions of cardinal environmental problems - that is the aim of environmental science.

Calls to protect environment alone will not deliver results. It is not an easy task - to harmonize human activities and development with preservation of natural environment. It does not depend on good will and willingness only, the essence is deeper - it is necessary to learn and apply fundamental regularities of interactions in the system "biosphere technosphere - noosphere". 


\section{THE PLACE OF ENVIRONMENTAL SCIENCE AMONG OTHER SCIENTIFIC FIELDS}

Based on that established above:

- the object of environmental science - interaction zones between technosphere and biosphere, - research methodology of environmental science - principles of system analysis, physical and chemical methods, modeling,

- the aim of environmental science - studies and application of interaction laws between elements of complex systems,

It can be concluded that environmental science fully complies with the criteria for autonomous science, it is not part of any other science and does not have other science as its part.

\section{CONCLUSIONS}

Analysis of the subject and structure of environmental science provides a short and concise definition of it:

Environmental science is the science that deals with structure, interaction laws and processes of multifactorial complex systems "technosphere - ecosphere" in order to ensure human existence that is viable and sustainable.

The rest of the information included in existing definitions of environmental science is the extended explanation of tasks and actions.

According to the author's view, they are the origin and structure of biogeophysical and technogenic systems and their components, functioning, energy and dynamics in interaction zones, the principles of rational utilization and reproduction of natural resources, the preservation and improvement of biological equilibrium and environmental quality, the principles and methods for development of environmentally friendly technological systems.

The last task directly relates to the sub-science "environmental engineering" that is determinative for the aim of environmental science.

Environmental engineering is the sub-science of environmental science that deals with technosystems, their operational processes affecting the environment and their regularities in engineering and technological applications that are based on principles of systems engineering and aimed at preservation of environmental quality.

\section{Literature}

[1] http://www.biology-online.org/dictionary/Environmental_Science

[2] http://www.thefreedictionary.com/environmental_science

[3] http://en.wikipedia.org/wiki/Glossary_of environmental_science

[4] http://www.newagepublishers.com/samplechapter/001281.pdf

[5]Keller Edward,A.,2008. Essential Environmental Science.

[6]Anger ,E.D.,Smith B.F.,1995.,Environmental Science: A Study of interrelationships.

[7] Jorgensen, S. E.,I.Johnson.,1989.,Principles of Environmental Science and Technology.

[8] Annotations of Latvia science sectors and subsectors ,1999., Latvia Council of Science act. (in Latvian).

[9] Nomenclature of doctors'of science degrees ,1998.,Latvia Council of Science act. (in Latvian). 
[10] Latvia education classification Regul;ations issued by the Cabinet of Ministers $\mathrm{Nr} 2675$.

[ 11] Cunningham, W. P.,Cunningham,M.,2008.,Environmental Global Concern.

[12]Haeckel, E.,1866., Art Form of Nature.

[13] Warming, E.,Vahl,M.,1925., Oecology of Plants -an Introduction to the Study of Plantcommunities.

[14] Andrewartha ,H.G., Birch ,L.C., 1984., The Ecological Web.

[15] Odum,E.P., 1961.,The strategy of Ecosystems Development. Science 164,262-270.

[16] Kelly, Evelyn B., 2005.,The Rise of Environmental Science.

[17] Walonic,D.S.,1993.,General Systems Theory

[18] Mitchell, M., 2009., Complexity. A Guided Tour .

[19] Rihani, S.,2002., Complex Systems Theory and Development Practice.

[20] Mitchell,M.,Newman, M., 2002.,. Complex Systems Theory and Evolution.

[21] Theilard de Chardin,1965., The Phenomenon of Man.

[22] Vernadsky ,V.V.,1944., Some Words about Noosphere, Uspehi sovremenoi biologii, 113-120.

[23]Bertalanffy,K.L.,1968., General System Theory. Foundations, Development, Applications.

[24] Prigogine, I.,1977., Self- Organization in Non-Equilibrium Systems .

[25].Altshuller,G.,2003., To Find Idea. Introduction in Solving Innovation Problem,.(in Russian).

[26] Hofstetter, P.,1998., Perspectives in Life Cycle Impact Assessment; A Structured Approach to Combine Models of the Technosphere, Ecosphere and Valuesphere.

[27] Hofstetter, P., Braunschweig A., Mettier M., Müller-Wenk R., Tietje O., 1999., Dominance Analysis in the Mixing Triangle, A Graphical Decision Support Tool for Product Comparisons. The Journal of Industrial Ecology, [28] Noviks,G., 2000., Environmentally Sustainable Technologies and Environmental quality indicators. International conference" City Environment Proceedings. 4-12. [29] Noviks, G.,2003., Development of Ecotechnology Complex Analysis System, Rēzeknes augstskolas zinātniskie raksti, 97-111,(in Latvian). [30] Noviks, G.,2007.,Motivation of waste treatment technology optimization. Environment. Technology .Resources. VI International scientific conference proceedings,87-101. ,(in Latvian)

[31] Noviks,G.,2003.,Ecotechnology- Physical and Technical Substantation of Pyrolysis . Environment. Technology. Resources. IV International scientific conference proceedings,191201. ,(in Latvian) 